\title{
Médiévales
}

Langues, Textes, Histoire

67 | automne 2014

Histoires de Bohême

\section{Valérie THEIS, Le Gouvernement pontifical du Comtat}

\section{Venaissin}

Rome, École française de Rome, 2012, 822 p. («Collection de l'École

française de Rome ", 464)

\section{Philippe Bernardi}

\section{(2) OpenEdition}

12 Journals

\section{Édition électronique}

URL : https://journals.openedition.org/medievales/7344

DOI : $10.4000 /$ medievales.7344

ISSN : $1777-5892$

Éditeur

Presses universitaires de Vincennes

\section{Édition imprimée}

Date de publication : 31 décembre 2014

Pagination : 197-199

ISBN : 978-2-84292-422-5

ISSN : 0751-2708

Référence électronique

Philippe Bernardi, «Valérie theıs, Le Gouvernement pontifical du Comtat Venaissin », Médiévales [En ligne], 67 | automne 2014, mis en ligne le 09 mars 2015, consulté le 22 avril 2022. URL : http://

journals.openedition.org/medievales/7344; DOI : https://doi.org/10.4000/medievales.7344

Ce document a été généré automatiquement le 22 avril 2022

Tous droits réservés 


\title{
Valérie THEIS, Le Gouvernement pontifical du Comtat Venaissin
}

\author{
Rome, École française de Rome, 2012, 822 p. («Collection de l'École \\ française de Rome », 464)
}

Philippe Bernardi

\section{RÉFÉRENCE}

Valérie THEIS, Le Gouvernement pontifical du Comtat Venaissin, Rome, École française de Rome, 2012, 822 p. («Collection de l'École française de Rome », 464)

1 Avec ce bel ouvrage issu de sa thèse de doctorat, Valérie Theis nous propose un de ces pas de côté qui mettent en évidence la force de nos présupposés et nous conduisent à envisager autrement, hors des lieux communs, une situation ou un objet historique familier. Dès la couverture, le ton est donné. Alors que l'on attendrait, pour illustrer la notion de "gouvernement pontifical», la masse imposante du Palais des Papes d'Avignon, c'est l'image plus discrète, presque estompée, du palais pontifical de Pontde-Sorgues qui est mise en avant. De ce dernier ne demeurent aujourd'hui que quelques maigres vestiges. Sa construction, menée de pair avec la réactivation d'un atelier de frappe monétaire pontifical, en 1317, n'en fut pas moins, comme cela est bien montré, l'un des maillons essentiels de l'affirmation de la souveraineté des papes sur cette partie de leurs états. Car, s'il est bien question de "gouvernement », c'est-à-dire des «techniques et procédures destinées à diriger la conduite des hommes »- suivant la définition de la notion que l'auteure emprunte à Michel Foucault -, c'est sur la mise en place de ce pouvoir, plus que sur son plein exercice, que porte cet ouvrage. L'image quelque peu statique d'un Gouvernement pontifical du Comtat Venaissin permanent et assuré ne représente ainsi que l'horizon d'une dynamique d'installation ou d'une progressive affirmation de domination dans lesquelles nous plonge le travail de Valérie Theis. Il ne s'agit pas, alors, d'envisager, à travers le gouvernement du Comtat Venaissin, la manière dont fut administrée cette partie excentrée des états pontificaux, 
mais d'examiner les moyens par lesquels la papauté sut, au tournant du XIV siècle, assurer la survie de l'institution.

2 La question, récurrente, sur les raisons de l'implantation de la papauté si loin de Rome a, en effet, longtemps éclipsé celle des moyens de cette installation, ramenant tout à un simple choix d'emplacement: le Comtat Venaissin plutôt que Rome ou une autre localité des états pontificaux. Mais le Comtat Venaissin, qui parait s'imposer comme une évidence depuis les travaux de Joseph Fornery ${ }^{1}$, est, comme le montre Valérie Theis, lui-même une construction de la papauté avignonnaise qui a dû se donner les moyens de modeler et de dominer ce territoire par des annexions, des acquisitions et la mise en place d'une administration efficace.

3 C'est à travers leurs actions que l'auteure nous propose d'appréhender l'intention des papes avignonnais. Des actions que l'auteure reprend chronologiquement dans une analyse subtile où chaque détail, chaque événement prend tout son relief. Les origines de cette histoire se trouvent dans le traité de Paris qui, en 1229, mit un terme à la croisade capétienne dans le Midi et vit le comte de Toulouse Raymond VII céder à l'Église romaine le marquisat de Provence. Ce n'est toutefois qu'avec la remise du Comtat Venaissin au pape Grégoire X, en 1274, que débute, à proprement parler, l'histoire du gouvernement pontifical de ce territoire. Cette histoire est, dans un premier temps, celle d'une succession de recteurs qui, du prieur des Hospitaliers de Saint-Gilles, Guillaume de Villaret, à Raymond Guilhem, seigneur de Budos et neveu du pape Clément $\mathrm{V}$, marquèrent de leur personnalité un gouvernement contesté, exercé pour partie à distance. Il faut attendre le pontificat de Jean XXII, inauguré en 1316, pour que s'affirme progressivement la domination pontificale sur le Comtat à travers une véritable politique de maîtrise du territoire, faite d'annexions, de donations, et qui culmine avec l'achat de la ville même d'Avignon par Clément VI, en 1348. C'est ce moment parachevant la domination pontificale sur cette région que Valérie Theis a choisi comme terme de son étude, laissant le lecteur au seuil de l'histoire d'un gouvernement victorieux.

4 Le livre de Valérie Theis comprend trois parties intitulées respectivement: "Aux sources de la domination », "Administrer le Venaissin » et «Devenir sujets du pape ». La première ("Aux sources de la domination ») déroule en une fresque alerte et précise les principales étapes de l'implantation de la papauté dans ce territoire. Ce premier volet campe pour le lecteur une galerie de portraits des principaux acteurs de la contestation ou de l'affirmation de la domination pontificale. Mais cette première partie donne aussi une place remarquable à la documentation écrite envisagée non seulement pour son contenu, mais également, "au-delà des lettres ", à travers sa production, sa conservation et son utilisation par la papauté en tant qu'outil de gouvernement et mémoire d'institutions en fonctionnement. C'est, ainsi, toute une administration qui se retrouve fort justement placée, aux côtés des personnages de premier plan, « aux sources de la domination ». L'auteure illustre ici magistralement les apports d'une réflexion sur la pratique de l'« écrit pragmatique » qu'elle a fortement contribué à engager par ailleurs avec ses travaux sur les comptabilités pontificales².

5 Le second «volet » de ce travail, et le plus volumineux, nous propose une approche de l'administration du Venaissin à travers l'étude minutieuse, systématique, des différents rouages de la machine administrative mise en place et des rapports établis entre les officiers pontificaux et les populations. C'est toutefois, en premier lieu, sur l'espace dans lequel s'exerçait la domination pontificale qu'est attirée l'attention du lecteur; 
une domination envisagée à travers ses manifestations matérielles. Valérie Theis nous engage ainsi, de manière très convaincante, à lire dans le passage de la recherche d'un lieu alternatif à Avignon (Pont-de-Sorgues) à un lieu complémentaire (Villeneuve-LèsAvignon) la marque de la solidité acquise par l'institution pontificale au début des années 1340. La dissociation entre le lieu de résidence du pape et le territoire sous sa domination (avant 1348, Avignon n'appartenait pas plus que Villeneuve-Lès-Avignon au Comtat) impliquait, comme le montre bien Valérie Theis, « d'en confier la gestion à un personnel bien distinct de la Curie mais, en revanche, très présent sur le terrain ». Et c'est de ce personnel que l'auteure nous propose, dans cette partie de son travail, un portrait extrêmement fouillé. Profil social, rôle financier, salaires et fonctions des différents officiers pontificaux sont ici détaillés avec une rigueur qui fait de cette partie de l'ouvrage un outil unique et indispensable pour aborder l'histoire médiévale du Comtat Venaissin. Mais, dans l'histoire du gouvernement pontifical que nous propose Valérie Theis, l'être humain ne s'efface pas devant sa fonction. Les officiers sont faits d'ambitions ; ils peuvent abuser de leur pouvoir... ce que nous montrent clairement les quelques carrières reconstituées. C'est que le territoire administré n'est pas de papier. Il est fait de richesses et de revenus qui circulent, fluctuent, et sur lesquels la papauté veille et influe.

6 La troisième partie de l'ouvrage, "Devenir sujets du pape ", met le pouvoir pontifical en perspective, le présentant dans sa confrontation aux autres pouvoirs en place dans le Comtat: celui des évêques, des vassaux ou des communautés. Elle nous livre, là encore, un panorama nuancé des jeux de pouvoir, des négociations et des pressions que suscita la mise en place de la domination pontificale. Le livre de Valérie Theis, bien loin de la monographie politico-administrative que pourrait laisser supposer son titre, nous offre une analyse remarquable sur le mode de mise en place d'un pouvoir au Moyen Âge. L'auteure y dénoue pour le lecteur l'entrelacs des actions menées par les souverains pontifes afin d'assurer leur domination sur le Comtat Venaissin et replace avec beaucoup de finesse ces actions dans le contexte troublé de la situation de la papauté entre XIII et XIV siècles. L'un des grands attraits de ce travail réside dans le fait que la complexité des situations ne se trouve aucunement sacrifiée au nom d'une quelconque simplification ou généralisation. L'Histoire se trouve ici clairement faite d'histoires multiples, de dossiers ${ }^{3}$ divers qui viennent nourrir le récit et sont autant de facettes d'une situation qui, pour être administrative, n'en demeure pas moins humaine.

\section{NOTES}

1. L'ouvrage de Joseph Fornery (Histoire du Comté Venaissin et de la ville d'Avignon, Avignon, 1909) a été écrit au début du XVIII ${ }^{\mathrm{e}}$ siècle mais publié uniquement en 1909, en même temps que l'étude de Claude Faure, Étude sur l'administration et l'histoire du Comtat Venaissin du XIII siècle au Xve siècle (1229-1417), Paris-Avignon, 1909 («Recherches historiques et documents sur Avignon, le Comtat Venaissin et la principauté d'Orange »). 
2. Voir le dossier consacré aux comptabilités pontificales qu'elle a dirigé avec Étienne Anheim, dans les Mélanges de l'École Française de Rome, Moyen Âge, 118/2 (2006).

3. On peut renvoyer à certains de ces « dossiers " présentés de manière autonome et développés par Valérie Theis dans divers articles, notamment: «Histoire d'eau. Les conflits sur l'approvisionnement en eau de Carpentras (XIV -XV siècles) ", Médiévales, 53 (2007), p. 23-38, ou «Jean XXII et l'expulsion des juifs du Comtat Venaissin », Annales HSS, 67/1 (2012), p. 41-77. 